Document downloaded from:

http://hdl.handle.net/10251/64529

This paper must be cited as:

Meseguer-Lloret, S.; Torres-Cartas, S.; Catalá-Icardo, M.; Gómez Benito, C. (2016).

Selective and sensitive chemiluminescence determination of MCPB: flow injection and liquid chromatography. Applied Spectroscopy. 70(2):312-321. doi:10.1177/0003702815620133.

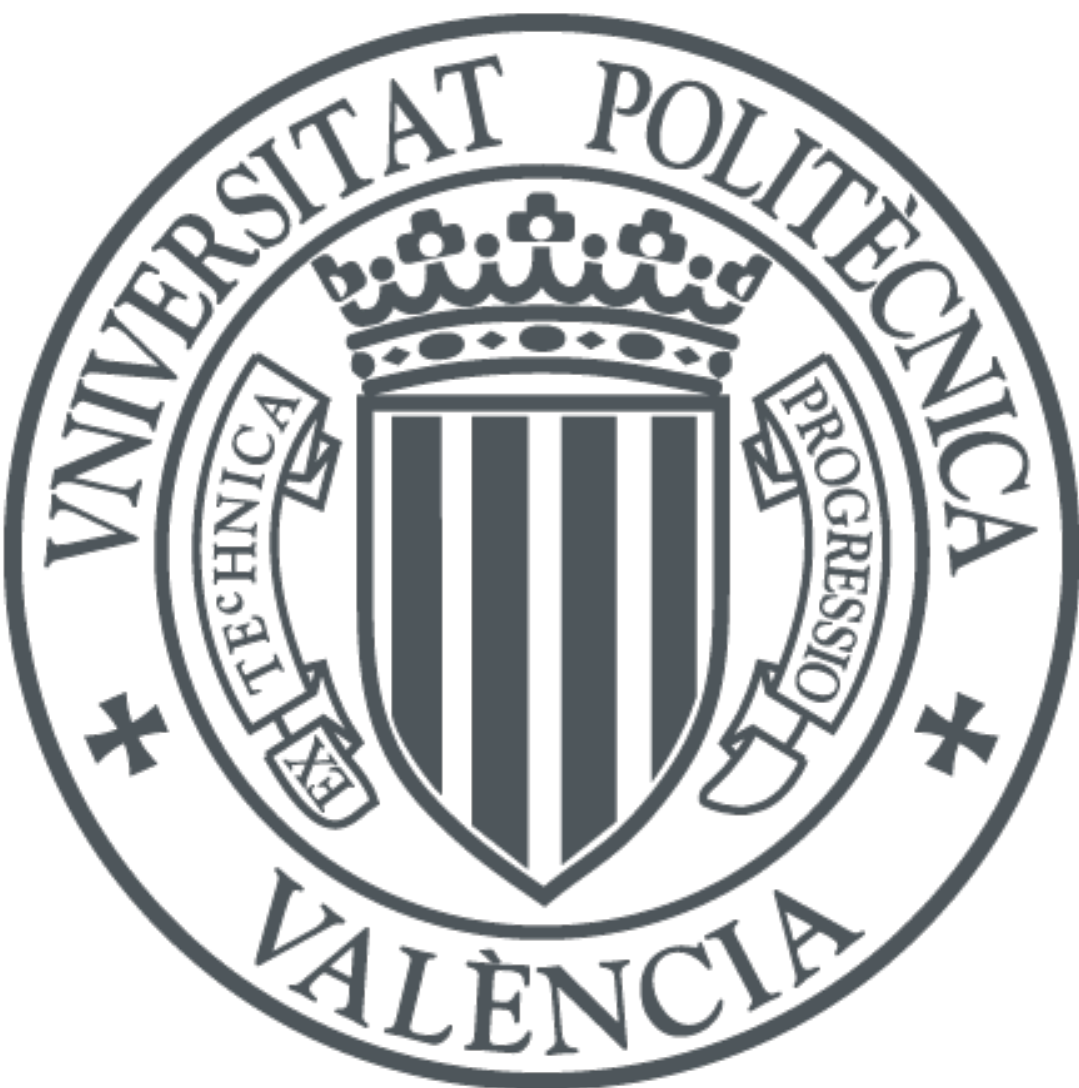

The final publication is available at

http://dx.doi.org/10.1177/0003702815620133

Copyright SAGE Publications (UK and US)

Additional Information

This paper was published in Applied Spectroscopy and is made available as an electronic reprint with the permission of OSA. The paper can be found at the following URL on the OSA website: http://dx.doi.org/10.1177/0003702815620133 . Systematic or multiple reproduction or distribution to multiple locations via electronic or other means is prohibited and is subject to penalties under law. 


\title{
SELECTIVE AND SENSITIVE CHEMILUMINESCENCE DETERMINATION OF MCPB: FLOW INJECTIN AND LIQUID
}

Susana Meseguer-Lloret*, Sagrario Torres-Cartas, Mónica Catalá-Icardo, Carmen GómezBenito

Instituto de Investigación para la Gestión Integrada de Zonas Costeras. Universitat Politècnica de València. C/ Paranimf nº 1,46730 Grao de Gandía, Valencia, Spain.

*Corresponding author. Tel: +34962849300; fax: +34962849333. E-mail address: sumello@qim.upv.es

\begin{abstract}
Two new chemiluminescence methods are described for the determination of herbicide MCPB. Firstly, a flow injection chemiluminescence (FI-CL) method is proposed. In this method, MCPB is photodegraded with a UV lamp and the photoproducts formed provide a great chemiluminescence signal when they react with ferricyanide in basic medium. Secondly, an HPLC chemiluminescence (HPLC-CL) method is proposed. In this method, before the photodegradation and CL reaction, the MCPB and other phenoxyacid herbicides are separated in a C18 column. The experimental conditions for the FI-CL and HPLC-CL methods are optimized. Both methods present good sensitivity, the detection limits being $0.12 \mu \mathrm{g} \mathrm{L}^{-1}$ and $0.1 \mu \mathrm{g} \mathrm{L}^{-1}$ (for FI-CL and HPLC-CL, respectively) when solid phase extraction is applied. Intra- and interday relative standard deviations are below 9.9\%. The methods have been satisfactorily applied to the analysis of natural water samples. FI-CL method can be employed for the determination of MCPB in simple water samples and for the screening of complex water samples in a fast, economic and simple way. The HPLC-CL method is more selective, and allows samples that have not been resolved with the FI-CL method to be solved.
\end{abstract}

Keywords: MCPB; flow injection; liquid chromatography; HPLC; chemiluminescence; photoreactor; solid phase extraction; SPE 


\section{INTRODUCTION}

MCPB, 4-(4-chloro-o-tolyloxy) butyric acid, is a chlorophenoxy acid herbicide. It is employed as a pre- and post-emergence herbicide to control broad-leaved weeds ${ }^{1}$. MCPB is usually employed in the treatment of grass and cereal crops, and is more selective than 2-methyl-4chlorophenoxyacetic acid (MCPA) for the treatment of leguminous crops such as peas and beans. It can be found in different herbicide formulations such as Tropotox, Tropotox Plus or Thistrol. Regarding its toxicity, MCPB is an irritant for the respiratory tract and eyes.

In the treatment of weeds, some pesticides are applied directly onto crops, causing the soluble residues of the pesticides employed to appear in ground and surface waters. The maximum residue limit for pesticides, established by the Regulations of the Hydraulic Public Domain for dumping of pesticides ${ }^{2}$, is $0.05 \mathrm{mg} \mathrm{L}^{-1}$. In waters intended for human consumption, the maximum residue limit (MRL) has been set at $0.1 \mu \mathrm{g} \mathrm{L}^{-1}$ for total pesticides, and $0.05 \mu \mathrm{g} \mathrm{L}^{-1}$ for individual pesticides ${ }^{3}$. With these considerations, the development of quick and easy analytical methods for the screening and quantification of pesticides of interest, such as MCPB, is a priority.

Most of the analytical methods developed in recent years, for the determination of the phenoxyacid herbicides in water samples, are based on the separation of the pesticides by high performance liquid chromatography (HPLC) with diode array, ultraviolet (UV), coulometric and mass (MS) detection. These methods propose combining HPLC with preconcentration or extraction techniques such as supramolecular solvent-based microextraction ${ }^{4}$, molecularly imprinted polymers ${ }^{5-6}$ and solid phase extraction (SPE) with C18 cartridges $^{7}$ or with poly(divinylbenzene-co-N-vinylpirrolidone) sorbent ${ }^{8}$. Other methods involve the separation of the pesticides by gas chromatography (GC) with MS detection combined with derivatization techniques ${ }^{9}$ or with extraction techniques such as phase transfer microextraction ${ }^{10}$ and liquidliquid extraction combined with dispersive $\mathrm{SPE}^{11}$.

Photochemical fluorimetry has been proposed for total chlorophenoxyacids determination ${ }^{12}$, and more recently, a method based on negative electrospray ionization-ion mobility spectrometry ${ }^{13}$ has also been developed. For the great majority of these methods, detection limits are in the range of $\mathrm{ng} \mathrm{L}^{-1}$, and some of them provide values in the range of $\mu \mathrm{g} \mathrm{L}^{-1}$. However, many of these methods have long and tedious derivatization or extraction procedures and/or expensive detection systems such as MS. 
In contrast, flow injection (FI) techniques provide properties such as rapidity, reproducibility and a high automation level with simple instrumentation. The combination of these FI techniques with chemiluminescence (CL) detection provides highly sensitive systems through the use of reactions of the analytes or their derivatives with strong oxidants. Many methods have recently been developed employing the FI-CL combination to determine pesticides such as carbaryl ${ }^{14}$, benfuresate ${ }^{15}$, dimethoate ${ }^{16}$, fenamiphos $^{17}$, atrazine ${ }^{18}$, thiacloprid $^{19}$ and MCPA ${ }^{20}$ among others.

Although it has been extensively proved that these FI-CL systems have very good sensitivity and throughput, the lack of selectivity is usually their main disadvantage. Therefore, methods combining HPLC separation with CL detection have been developed in recent years for the separation of pesticides such as organothiophosphorus ${ }^{21}$, N-methylcarbamates ${ }^{22}$, phenoxyl-type $\mathrm{N}$-methylcabamates ${ }^{23}$ and benzoylureas ${ }^{24}$. To the authors' knowledge, this combination (HPLC-CL) has not yet been employed with phenoxyacid herbicides.

In this paper, we have developed two new CL methods for the determination of phenoxyacid herbicide MCPB. The first one is a FI-CL method, which provides great sensitivity for the screening of this pesticide in routine laboratories. The MCPB is photodegraded in the FI system and the photoproducts react with ferricyanide in basic medium. To improve the selectivity in MCPB determination, a second HPLC-CL method has been developed, based on the same CL reaction performed post-column. The optimization of the physical and chemical parameters of both methods was carried out, and their analytical figures of merit were described. Both methods were applied to the screening and quantification of MCPB in natural water samples after a SPE procedure.

\section{EXPERIMENTAL}

\subsection{Reagents and solutions}

All aqueous solutions were prepared in Milli-Q water (Millipore, Bedford, MA, USA) and all reagents were of analytical grade.

The chemical reagents employed were: $\mathrm{HCl} 37 \%, \mathrm{Ce}\left(\mathrm{SO}_{4}\right)_{2} \cdot 4 \mathrm{H}_{2} \mathrm{O}, \quad \mathrm{KIO}_{4}, \quad \mathrm{KI}$, $\mathrm{CH}_{3} \mathrm{COONa} \cdot 3 \mathrm{H}_{2} \mathrm{O}$, fluorescein and formic acid were purchased from Scharlau (Barcelona, Spain); $\mathrm{H}_{3} \mathrm{PO}_{4} \quad 85 \%, \quad \mathrm{KMnO}_{4}, \quad \mathrm{~K}_{3}\left(\mathrm{Fe}(\mathrm{CN})_{6}\right), \quad \mathrm{K}_{2} \mathrm{~S}_{2} \mathrm{O}_{8}, \quad \mathrm{NaH}_{2} \mathrm{PO}_{4} \cdot 2 \mathrm{H}_{2} \mathrm{O}, \quad \mathrm{K}_{2} \mathrm{SO}_{4}, \quad \mathrm{NaOH}$, 
$\mathrm{Na}_{2} \mathrm{CO}_{3} \cdot 10 \mathrm{H}_{2} \mathrm{O}$, Eosyn $\mathrm{Y}$ and Triton X-100 from Panreac (Barcelona, Spain); $\mathrm{H}_{2} \mathrm{SO}_{4} 96 \%$, $\mathrm{H}_{2} \mathrm{O}_{2} 36 \%$, rhodamin B, ethanol, methanol and acetonitrile from Merck (Darmstadt, Germany); sodium dodecyl sulphate (SDS), cetyltrimethylammonium bromide (CTAB) and $\beta$-ciclodextrin from Fluka (Steinheim, Germany); and riboflavin and hexadecyl phosphate (HDO) from Sigma (St. Louis, MO).

In the interference study, cations tested were prepared from chlorides $\left(\mathrm{NH}_{4}^{+}, \mathrm{Ca}^{2+}, \mathrm{Cr}^{3+}, \mathrm{Pb}^{2+}\right.$, $\mathrm{Na}^{+}, \mathrm{Mg}^{2+}, \mathrm{Cd}^{2+}$ and $\mathrm{K}^{+}$(Panreac) and $\mathrm{Co}^{2+}, \mathrm{Ni}^{2+}, \mathrm{Fe}^{3+}$ (Scharlau)) or from sulphates $\left(\mathrm{Fe}^{2+}\right.$, $\mathrm{Mn}^{2+}, \mathrm{Zn}^{2+}$ and $\mathrm{Cu}^{2+}$ (Panreac)). Nitrite, nitrate (Probus, Badalona, Spain) and chromate (Scharlau) sodium anions were also tested.

MCPB and other phenoxyacid herbicides such as Clofibric acid, Cloprop, 4Chlorophenoxyacetic acid (4-CPA), Diclofop-methyl, Fenoxaprop, Haloxyfop, 2-methyl-4chlorophenoxyacetic acid (MCPA), Mecoprop (MCPP) and Propaquizofop were purchased from Riedel de Haën (Seelze, Germany). Stock standard solutions of $1000 \mathrm{mg} \mathrm{L}^{-1}$ of pesticide were prepared by dissolving the pure compound in acetonitrile (except MCPA, which was dissolved in methanol). These solutions were stored in the dark at $4^{\circ} \mathrm{C}$. Working standard solutions were prepared by diluting the stock standard solution with water.

The solutions employed as mobile phases were filtered with $0.45 \mu \mathrm{m}$ nylon phenex filter membranes (Phenomenex, Torrance, CA, USA) and degassed in an ultrasonic bath for 15 minutes before use.

\subsection{Apparatus}

The FI-CL analysis of MCPB was carried out by means of a Gilson Minipuls peristaltic pump (Worthington, OH, USA) furnished with polyvinyl chloride pumping tubes (Omnifit, Cambridge, UK). The flow system was designed with PTFE coil of $0.8 \mathrm{~mm}$ i.d. A six-port injection valve (IV, Model V-450, Upchurch Scientific, Oak Harbor, WA), a photoreactor (Ph) consisting of a $400 \mathrm{~cm}$ length of PTFE tubing helically coiled around a $15 \mathrm{~W}$ low pressure mercury lamp (Sylvania, Madrid, Spain) and a water bath (J.P. Selecta, Barcelona, Spain) were required. The flow cell was a flat-spiral glass tube of $1 \mathrm{~mm}$ i.d. and $3 \mathrm{~cm}$ total diameter and the photodetector package (CLD) was a P30CWAD5 type 9125B photomultiplier tube supplied by Electron Tubes (Uxbridge, United Kingdom); they were located in a laboratory-made light- 
tight box. The output was connected to a computer equipped with a counter-timer, also supplied by Electron Tubes.

The HPLC-CL analysis of MCPB was carried out by means of a chromatographic system (Jasco Analytica, Madrid, Spain) for the separation step and a flow system for the photodegradation and the oxidation steps. The chromatographic system consisted of a quaternary gradient pump (Jasco PU-2089 Plus), an intelligent autosampler (Jasco AS-2055 Plus), a photodiode array detector (DAD) (Jasco MD-2018 Plus) and a CL detector (Jasco CL2027 Plus) linked to a data system (Jasco LC-NET/ADC). The separation column was a Kinetex 2.6 $\mu \mathrm{m}$ C18 100A 100x4.6 mm (Phenomenex, Torrance, CA, USA). The flow system consisted of a photoreactor ( $\mathrm{Ph}$ ) (the same as in FI-CL) and a peristaltic pump furnished with polyvinyl chloride pumping tubes and PTFE coil ( $0.8 \mathrm{~mm}$ i.d.).

\subsection{Procedures}

The optimal FI-CL manifold is shown in Figure 1a. The standard or sample (S) flowed at 3.6 $\mathrm{mL} \mathrm{min}^{-1}$ along the photoreactor and the photodegraded solution filled the sample loop (L) of 1 $\mathrm{mL}$, which was submerged in the water bath at $70^{\circ} \mathrm{C}$. The carrier stream $(\mathrm{C}$, water $)$ flowed at $6.8 \mathrm{~mL} \mathrm{~min}^{-1}$ and a portion of tube of $1 \mathrm{~mL}$ was also submerged in the water bath. The oxidant stream $(\mathrm{O}, 0.5 \mathrm{mM}$ ferricyanide in $0.75 \mathrm{M} \mathrm{NaOH})$ at $2.8 \mathrm{~mL} \mathrm{~min}^{-1}$ merged with the heated carrier stream just before the detection cell.

The optimal HPLC-CL manifold is shown in Figure 1b. An acetonitrile-phosphoric acid (25 $\mathrm{mM}$ ) mobile phase flowing at $1 \mathrm{ml} \mathrm{m^{-1 }}$ was employed, the gradient elution being: 20:80 for 3 minutes; 60:40 at 4 minutes; 65:35 at 8 minutes; and 20:80 from 9 to 13 minutes. $20 \mu \mathrm{L}$ of the sample (S) were inserted in the system and, after the analyte separation, DAD signal was registered. Next, the eluate was mixed with a buffer solution (B, $0.1 \mathrm{M}$ phosphate buffer $\mathrm{pH} 7)$ flowing at $1.5 \mathrm{~mL} \mathrm{~min}^{-1}$. The mixture passed through the photoreactor ( $3 \mathrm{~m} \mathrm{x} 0.5 \mathrm{~mm}$ i.d.), and finally, the photoproducts merged with the oxidant $(\mathrm{O})$ stream $(4 \mathrm{mM}$ ferricyanide in $0.5 \mathrm{M}$ $\mathrm{NaOH}$ ) flowing at $2 \mathrm{~mL} \mathrm{~min}^{-1}$. The $\mathrm{CL}$ emission signal was registered at $60^{\circ} \mathrm{C}$ (temperature of the detection cell). 


\subsection{SPE procedures}

SPE cartridges Strata SDBL $(100 \mu \mathrm{m}$ Styrene-divinylbenzene $200 \mathrm{mg} 6 \mathrm{~mL}$ Phenomenex, Torrance, CA, USA) were used for both the FI-CL and the HPLC-CL methods in order to avoid interferences from matrix components and to introduce a pre-concentration step.

For the FI-CL method, the cartridges were conditioned with $5.0 \mathrm{~mL}$ of methanol and $10 \mathrm{~mL}$ of $5 \mathrm{mM} \mathrm{HCl}$. Then, variable volumes of standard solution $(50-1000 \mathrm{~mL})$ prepared in water were transferred to the cartridge. In order to wash the cartridge, $20 \mathrm{~mL}$ of $5 \mathrm{mM} \mathrm{HCl}$ and $10 \mathrm{~mL}$ of water were flushed. After that, the cartridge was dried under vacuum for 5 minutes and elution was performed by adding $1.5 \mathrm{~mL}$ of acetonitrile. The eluate was diluted up to $50 \mathrm{~mL}$ with water prior to FI-CL analysis.

For the HPLC-CL method, the cartridges were conditioned with $5.0 \mathrm{~mL}$ of methanol and 10 $\mathrm{mL}$ of $5 \mathrm{mM} \mathrm{HCl}$. Then, variable volumes of aqueous standard solution $(25-1000 \mathrm{~mL})$ were transferred to the cartridge. In order to wash the cartridge, $25 \mathrm{~mL}$ of $5 \mathrm{mM} \mathrm{HCl}$ were flushed. After that, the cartridge was dried under vacuum for 5 minutes and elution was performed with $1 \mathrm{~mL}$ of acetonitrile. The eluate was filtered with PTFE syringe filters $(0.22 \mu \mathrm{m}$, Phenomenex, Torrance, CA, USA) prior to HPLC-CL analysis.

\subsection{Sample preparation}

Water samples from different sources were analysed. They were named as follows: tap water (S1 and S2), mineral water (S3), seawater (S4), spring water (S5) and well water (S6). Samples were collected in plastic bottles, filtered under vacuum with Whatman cellulose filters of $6 \mu \mathrm{m}$ (England) and stored at $4^{\circ} \mathrm{C}$ in a refrigerator.

For the FI-CL method, a volume of water sample $(25 \mathrm{~mL}$ for $\mathrm{S} 1 ; 100 \mathrm{~mL}$ for $\mathrm{S} 2, \mathrm{~S} 4, \mathrm{~S} 5$ and S6; and $50 \mathrm{~mL}$ for S3) acidified with $5 \mathrm{mM} \mathrm{HCl}$ was spiked with MCPB, and SPE procedure was applied. Samples S3, S4, S5 and S6 were fortified with 25 and $50 \mu \mathrm{g} \mathrm{L}^{-1}$ of MCPB; S1 was fortified with 25 and $100 \mu \mathrm{g} \mathrm{L}^{-1}$ of MCPB; and S2 was fortified with 16 and $32 \mu \mathrm{g} \mathrm{L}^{-1}$ of MCPB. For all samples, each concentration level was prepared in triplicate. The concentration levels selected for each sample did not depend on the type of sample. They were selected randomly as samples were analysed at different times in the research. 
For the HPLC-CL method, $100 \mathrm{~mL}$ of water sample spiked with 5 or $10 \mu \mathrm{g} \mathrm{L}^{-1}$ of MCPB were treated with SPE procedure (both concentration levels in triplicate). Moreover, SPE was applied to $1000 \mathrm{~mL}$ of non-spiked water samples to evaluate the presence or absence of MCPB with the highest preconcentration factor.

\section{RESULTS AND DISCUSSIONS}

\subsection{Optimization of the FI-CL method}

The optimal conditions were identified by selecting the parameters that provided the maximum CL signal with good repeatability (relative standard deviation, \%RSD, below $10 \%$ for five standard insertions). The initial conditions of the FI-CL system are based on our previous studies for the determination of $\mathrm{MCPA}^{20}$.

\subsubsection{Selection of the oxidation system}

A standard of $5 \mathrm{mg} \mathrm{L}^{-1}$ of MCPB was used to assess the CL signal generated with different oxidation systems. For each oxidant, three levels of concentration between $3 \cdot 10^{-3}$ and $7 \cdot 10^{-4} \mathrm{M}$ were assayed. The oxidation systems were: $\mathrm{KMnO}_{4}, \mathrm{Ce}\left(\mathrm{SO}_{4}\right)_{2}, \mathrm{~K}_{2} \mathrm{~S}_{2} \mathrm{O}_{8}$ and $\mathrm{KIO}_{4}$ in $1.8 \mathrm{M}$ $\mathrm{H}_{2} \mathrm{SO}_{4}$, and $\mathrm{K}_{3} \mathrm{Fe}(\mathrm{CN})_{6}$ and $\mathrm{H}_{2} \mathrm{O}_{2}$ in $1 \mathrm{M} \mathrm{NaOH}$. The results showed that only $\mathrm{KMnO}_{4}$ in $\mathrm{H}_{2} \mathrm{SO}_{4}$ and $\mathrm{K}_{3} \mathrm{Fe}(\mathrm{CN})_{6}$ in $\mathrm{NaOH}$ provided $\mathrm{CL}$ signal, but with the latter, the signal was higher. Therefore, $\mathrm{K}_{3} \mathrm{Fe}(\mathrm{CN})_{6}$ in $\mathrm{NaOH}$ was selected as the oxidation system.

Then, the optimization of ferricyanide concentration was carried out in the range $1 \cdot 10^{-5}-9 \cdot 10^{-3}$ $\mathrm{M}$ (with $1 \mathrm{M} \mathrm{NaOH}$ as oxidation medium). The maximum CL signal was obtained with $\mathrm{K}_{3} \mathrm{Fe}(\mathrm{CN})_{6} 5 \cdot 10^{-4} \mathrm{M}$. With this optimal ferricyanide concentration, the oxidation medium $(\mathrm{NaOH})$ was varied between $0.5-2 \mathrm{M}$, and the maximum emission was obtained with $0.75 \mathrm{M}$ $\mathrm{NaOH}$. Therefore, the oxidation system selected was $5 \cdot 10^{-4} \mathrm{M} \mathrm{K}_{3} \mathrm{Fe}(\mathrm{CN})_{6}$ in $0.75 \mathrm{M} \mathrm{NaOH}$.

\subsubsection{Selection of the photodegradation medium}

In this section, the sample channel (S, Figure 1a) was divided into two sub-channels in order to introduce the sample and the photodegradation medium separately. Three photodegradation media were initially assayed with a standard of $5 \mathrm{mg} \mathrm{L}^{-1}$ of MCPB: $0.1 \mathrm{M} \mathrm{H}_{2} \mathrm{SO}_{4}, 0.1 \mathrm{M} \mathrm{NaOH}$ and water. The best signal was obtained with water. Then, different buffer solutions $(0.1 \mathrm{M}$ 
acetic/acetate $\mathrm{pH} 4$ and 5, and $0.1 \mathrm{M}$ dihydrogenphosphate/hydrogenphosphate $\mathrm{pH} \mathrm{6,7}$ and 8) were tested. Only the buffer solution $0.1 \mathrm{M}$ acetic/acetate $\mathrm{pH} 5$ slightly increased the CL signal $(5 \%)$ and to simplify the system, water was selected as the photodegradation medium.

\subsubsection{Influence of sensitizers on the CL signal}

For this sub-section and in all subsequent cases, a $0.5 \mathrm{mg} \mathrm{L}^{-1}$ standard of MCPB was used. Common sensitizers of the CL reactions were assayed in the photodegradation step and in the oxidation step by dividing the sample $(\mathrm{S})$ or the oxidant channel $(\mathrm{O}$, Figure 1a), respectively into two sub-channels. The CL signal was registered in the presence and absence of sensitizers.
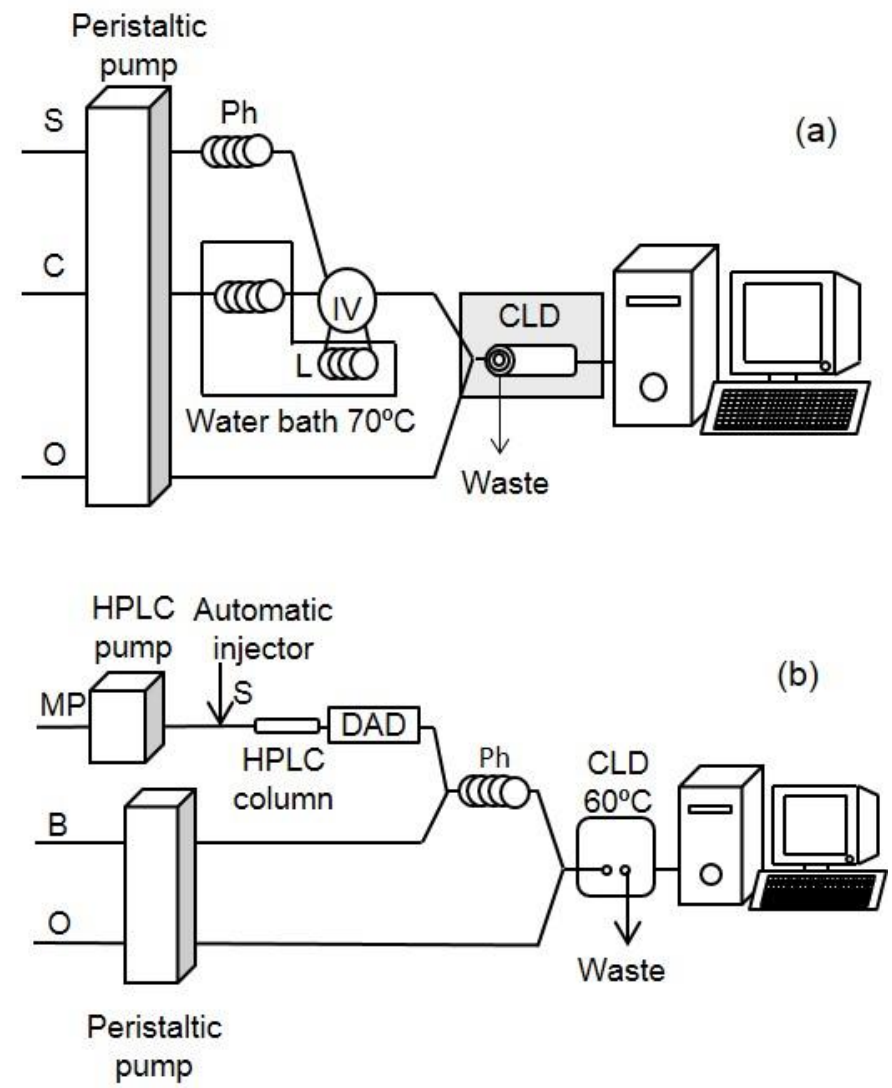

Figure 1. (a) FI-CL manifold (b) HPLC-CL manifold. S: standard or sample; C: carrier; O: oxidant; Ph: photoreactor; L: loop; IV: injection valve; CLD: chemiluminescence detector; MP: mobile phase; B: buffer solution

The sensitizers assayed were: $0.5 \%$ formic acid, $20 \%$ ethanol, $20 \%$ methanol, $20 \%$ acetonitrile, $1.2 \% \beta$-cyclodextrine, $0.6 \%$ Triton X-100, 0.5\% HDP, 1.2\% SDS, 0.06\% CTAB, $0.1 \mathrm{mM}$ riboflavine, $0.1 \mathrm{mM}$ fluorescein, $0.1 \mathrm{mM}$ eosyn yellow and $0.1 \mathrm{mM}$ rhodamine $\mathrm{B}$. 
None of the sensitizers significantly enhanced the CL signal, either in the photodegradation step or in the oxidation step. Hence, their use was discarded.

\subsubsection{Selection of the flow rates}

Photodegradation and oxidation flow rates were studied separately.

The time of exposure to UV light was varied by changing the flow rate of the sample channel (S) between 0.7 and $3.2 \mathrm{~mL} \mathrm{~min}^{-1}$, with fixed values for the carrier channel $\left(\mathrm{C}, 3.4 \mathrm{~mL} \mathrm{~min}^{-1}\right)$ and oxidant channel $\left(\mathrm{O}, 1.4 \mathrm{~mL} \mathrm{~min}^{-1}\right)$. The emission increased by raising the velocity of $\mathrm{S}$ channel and remained stable above $1.6 \mathrm{~mL} \mathrm{~min}^{-1}$. Thus, $1.8 \mathrm{~mL} \mathrm{~min}^{-1}$ was selected as the optimal flow rate for the sample channel.

Next, the flow rates of the carrier channel (C) and the oxidant channel $(\mathrm{O})$ were varied simultaneously in the ranges $1.7-9.9 \mathrm{~mL} \mathrm{~min}^{-1}$ and $0.7-4.1 \mathrm{~mL} \mathrm{~min}^{-1}$, respectively. It was observed that the CL signal increased by increasing the flow rate and remained stable above 6.8 $\mathrm{mL} \mathrm{min}^{-1}$ for the carrier channel and $2.8 \mathrm{~mL} \mathrm{~min}^{-1}$ for the oxidant channel. Therefore, these were the selected flow rates.

\subsubsection{Selection of the sample volume}

In order to select the optimal sample volume, this parameter was varied between 0.06 and 1 $\mathrm{mL}$, and the CL signal increased by raising the sample volume up to $0.8 \mathrm{~mL}$ from which point it remained stable. Hence, the selected sample volume was $1 \mathrm{~mL}$.

\subsubsection{Selection of the temperature}

In order to study the influence of the temperature on the CL signal, a portion of tube of $1 \mathrm{~mL}$ was added to the oxidant and to the carrier channels before the injection valve. These tubes and the loop were introduced into a water bath at temperatures between $20-70^{\circ} \mathrm{C}$. Higher temperatures were not assayed to avoid the formation of bubbles.

The heating of the oxidant reagent brought instability of the signal; consequently, this channel was not heated. Meanwhile, it was observed that by increasing the temperature of the carrier and the sample loop, the signal increased throughout the studied interval. Thus, $70^{\circ} \mathrm{C}$ was selected as the optimal temperature. 


\subsection{Optimization of the HPLC-CL method}

\subsubsection{Preliminary studies: Selection of the organic solvent for the mobile phase}

The presence of an organic solvent usually causes a decrease in the emission signal of CL reactions with strong oxidants ${ }^{21}$. However, the mobile phases employed in chromatographic systems usually involve the presence of an organic solvent such as methanol or acetonitrile.

The influence of organic solvents on the CL signal of MCPB was evaluated with the FI-CL method. The emission of a standard of $0.5 \mathrm{mg} \mathrm{L}^{-1}$ of MCPB was measured with four photodegradation media (water, 50\% acetonitrile, 50\% methanol and 20\% ethanol). A great decrease in the CL emission of MCPB was observed (compared with the results in water) when the organic solvents were introduced into the system: the signal decreased by $74.7 \%$ with acetonitrile, by $85.0 \%$ with ethanol, and almost disappeared when methanol was employed. As an organic solvent is needed for the chromatographic separation, acetonitrile was selected as the organic solvent for the mobile phase.

\subsubsection{Selection of the column and the composition of the mobile phase}

In the great majority of the analytical procedures described in the literature, a C18 chromatographic column is employed for the separation of this family of pesticides. The usual mobile phases contain an acid (such as phosphoric or acetic) and an organic solvent (mainly acetonitrile or methanol) in gradient elution mode ${ }^{6-8,25}$. In some cases, a PLRP-S column with water:acetonitrile mobile phase ${ }^{26}$ or a Luna $\operatorname{PFP}(2)$ column with formic acid:acetonitrile mobile phase ${ }^{5}$ have been employed.

To carry out the selection of the column and mobile phases DAD signal was registered. A group of ten phenoxyacid herbicides, namely Clofibric acid, Cloprop, 4-CPA, Diclofop-methyl, Fenoxaprop, Haloxyfop, MCPA, MCPB, MCPP and Propaquizofop, were employed with the aim of assuring the selectivity of the chromatographic method by the separation of MCPB from other pesticides of the phenoxyacids family. The elution of the ten phenoxyacid herbicides was confirmed by the absorption spectra obtained with DAD.

A comparison in the retention time and resolution of the mixture of the ten pesticides with two different chromatographic columns was carried out: a C18 column and a Polystyrene

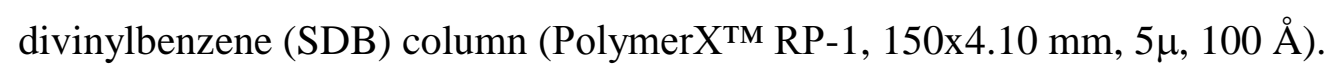


A $25 \mathrm{mM}$ phosphoric acid:acetonitrile mobile phase was employed with the C18 column because the phenoxyacids were not retained in the column in the absence of acidic conditions. With SDB column, a water:acetonitrile mobile phase was employed. Several elution gradients were assayed with both columns to ensure the separation of the mixture of herbicides. Finally, the gradient employed for the C18 column was: 80:20 for 4 minutes; then 40:60 at 5 minutes; 35:65 from 9 minutes to 13 minutes; and back to 80:20 at 14 minutes. The gradient employed for the SDB column was: 75:25 for 3 minutes; then 10:90 from 7 minutes to 13 minutes; and back to $75: 25$ at 14 minutes.

Figure 2 shows the DAD chromatograms obtained with the SDB and the C18 columns. As can be seen, the C18 column provided better resolution than the SDB column for the ten phenoxyacid herbicides assayed. The total chromatogram time was near 12 minutes in both cases, and the retention time for MCPB was near $7.5 \mathrm{~min}$ in both cases. With the $\mathrm{C} 18$ column narrow peaks were obtained, and with the SDB column MCPB was not resolved. Thus, the C18 column was selected.

\subsubsection{Photodegradation step}

The photodegradation step took place after the separation (see Figure 1b). The optimization was carried out with a ferricyanide concentration of $5 \mathrm{mM}$ in $0.5 \mathrm{M} \mathrm{NaOH}$ and in all subsequent cases, a $2 \mathrm{mg} \mathrm{L}^{-1}$ standard of MCPB was employed.

The previous FI-CL optimization showed that the photodegradation step should be carried out in neutral conditions to obtain the best CL response for MCPB. As the HPLC separation required an acidic mobile phase ( $25 \mathrm{mM}$ phosphoric acid:acetonitrile), a $0.1 \mathrm{M} \mathrm{pH} 7$ phosphate buffer solution (Figure 1b) was post-column mixed, ensuring a neutral $\mathrm{pH}$ for the photodegradation step. 


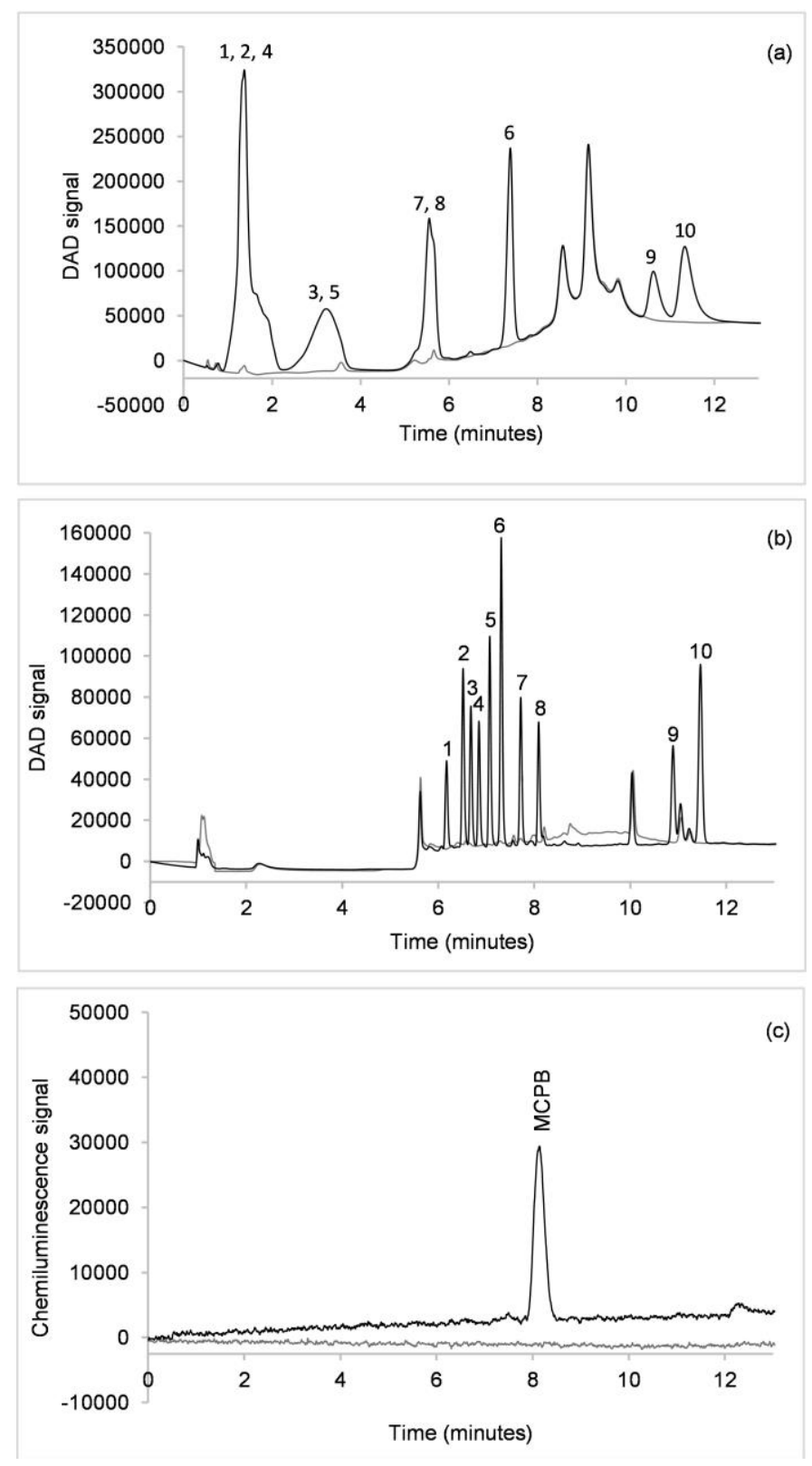

Figure 2. HPLC chromatograms for a blank (grey line) and a mixture of 10 phenoxyacid herbicides (black line): (a) with a SDB column $\left(10 \mathrm{mg} \mathrm{L}^{-1}\right.$ of each pesticide) and DAD detection (b) with a C18 column $\left(2 \mathrm{mg} \mathrm{L}^{-1}\right.$ of each pesticide $)$ and DAD detection, and (c) with a $\mathrm{C} 18$ column $\left(2 \mathrm{mg} \mathrm{L}^{-1}\right.$ of each pesticide) and CL detection. (1) 4-CPA, (2) Cloprop, (3) Clofibric acid, (4) MCPA, (5) MCPP, (6) MCPB, (7) Fenoxaprop, (8) Haloxyfop, (9) Propaquizafop and (10) Diclofop

\subsubsection{Optimization of the CL reaction}

Table I summarizes the ranges of study and the optimum values for the temperature, the oxidant concentration and the flow rates. 
With the optimum oxidant concentration, $4 \mathrm{mM}$ ferricyanide in $0.5 \mathrm{M} \mathrm{NaOH}$, the temperature of the CL reaction was studied by heating the CL detector cell and the selected value was the maximum temperature allowed by the CL detector.

Regarding the flow rates, the mobile phase flowed at $1 \mathrm{~mL} \mathrm{~min}^{-1}$ to obtain a good separation of MCPB from other phenoxyacid pesticides. In HPLC systems, the chromatographic column prevents the use of high flow rates due to the loss of efficiency and the pressure increase. Thus, the CL signal was registered at different flow rates of buffer and oxidant (see Table I).

Table I. Optimization of the CL reaction in HPLC-CL method

\begin{tabular}{lcc}
\hline Parameter & Range of study & Optimum value \\
\hline$\left[\right.$ Ferricyanide] $\left(\mathrm{mol} \mathrm{L}^{-1}\right.$, in $\left.0.5 \mathrm{M} \mathrm{NaOH}\right)$ & $3.5 \cdot 10^{-4}-7 \cdot 10^{-3}$ & $4 \cdot 10^{-3}$ \\
Temperature $\left({ }^{\circ} \mathrm{C}\right)$ & $25-60$ & 60 \\
Buffer flow rate $\left(\mathrm{mL} \mathrm{min}^{-1}\right)$ & $0.25-1.5$ & 1.5 \\
Oxidant flow rate $\left(\mathrm{mL} \mathrm{min}^{-1}\right)$ & $1-4$ & 2 \\
\hline
\end{tabular}

\subsection{SPE procedures}

\subsubsection{SPE in HPLC-CL method}

Several SPE cartridges were assayed with the aim of selecting the one that provided the best recovery of MCPB. The cartridges C18 (Varian Bond Elut $200 \mathrm{mg} 3 \mathrm{~mL}$ ), Strata X (Phenomenex $200 \mathrm{mg} 6 \mathrm{~mL}$ ) and SDBL (Phenomenex $200 \mathrm{mg} 6 \mathrm{~mL}$ ) were assayed with a 25 $\mathrm{mL}$ standard of $0.16 \mathrm{mg} \mathrm{L}^{-1}$ of MCPB (in $1 \mathrm{mM} \mathrm{HCl}$ for C18 and Strata X). The elution was carried out with $2 \mathrm{~mL}$ of acetonitrile (final concentration of MCPB $2 \mathrm{mg} \mathrm{L}^{-1}$ ). The percentages of recovery $(n=2)$ of MCPB related to a standard without SPE were: $93 \pm 2$ for C18, $73.1 \pm 3$ for Strata $X$ and $94.8 \pm 1.4$ for SDBL. SDBL was the selected cartridge because acidification of the standards was not necessary.

The volume of acetonitrile employed for the elution step was tested between 0.6-2 mL. Recoveries were $41.8 \%, 97 \%, 103.7 \%, 94.8 \%$ for $0.6,1.0,1.5$ and $2.0 \mathrm{~mL}$ of acetonitrile, respectively. Thus, $1 \mathrm{~mL}$ was selected as the elution volume to obtain the maximum preconcentration factor without loses of signal. 
Finally, standards of 25, 50, 100, 250 and $500 \mathrm{~mL}$ (initial MCPB concentrations of 20, 10, 5, 2 and $1 \mu \mathrm{g} \mathrm{L}^{-1}$, respectively and final MCPB concentration $0.5 \mathrm{mg} \mathrm{L}^{-1}$ ) were processed. The percentages of recovery of MCPB $(n=2)$ related to a standard without SPE were $(100.2 \pm 0.3)$, (104 \pm 13$),(114 \pm 17),(89.8 \pm 9),(88.5 \pm 8)$ for $25,50,100,250$ or $500 \mathrm{~mL}$, respectively. As the percentages of recovery were near $100 \%$, we concluded that there are no losses of signal after the whole SPE-HPLC-CL procedure.

The proposed HPLC-CL method can be applied to the determination of MCPB with a preconcentration factor of 500 when SPE with SDBL cartridges is applied.

\subsubsection{SPE in FI-CL method}

The SDBL cartridge was employed and the elution was carried out with $1.5 \mathrm{~mL}$ of acetonitrile. Aqueous standards of 50, 100, 250, 500 and $1000 \mathrm{~mL}$ (initial MCPB concentrations of 25, 12.5, $5,2.5$ and $1.25 \mu \mathrm{g} \mathrm{L}^{-1}$, respectively) were processed.

The application of the SPE procedure led to a decrease in the CL signal of $34 \%$ (related to standard without SPE) due to the presence of acetonitrile and some interfering residues. Therefore, in recovery studies the $50 \mathrm{~mL}$ standard, with SPE but without preconcentration, was employed as reference. The percentages of recovery of MCPB $(n=2)$ with the different volumes assayed were $(93.8 \pm 0.1),(96 \pm 2),(110 \pm 10)$ and $98.9(\mathrm{n}=1)$ for $100,250,500$ and $1000 \mathrm{~mL}$ of standard, respectively. These recoveries near $100 \%$ indicated that there were no loses of signal independently of the standard volume assayed.

A preconcentration factor of 20 can be reached in the determination of MCPB with the proposed FI-CL method.

\subsection{Analytical Performance}

Linear calibration curves were obtained when the chemiluminescence signal in FI-CL method (or peak area in the HPLC-CL method) was represented versus the MCPB concentration (C, $\mu \mathrm{g}$ $\mathrm{L}^{-1}$ ). Table II summarizes the figures of merit for linear calibration curves obtained for both methods at different working conditions. 


\subsubsection{Figures of merit with the FI-CL method}

The calibration curve for FI-CL method was obtained with $50 \mathrm{~mL}$ aqueous standards with SPE (Table II). In this condition, SPE allowed to clean the sample but no preconcentration was achieved. The calibration curve with SPE is necessary because, as it has been mentioned above, the acetonitrile and other SPE residues decreased the CL signal. As the recoveries of MCPB have been demonstrated to be near $100 \%$ independently of the sample volume assayed (see Section 3.3.2), this calibration curve can be employed to analyse samples that require preconcentration taking into account the preconcentration factor.

Table II. Figures of merit for FI-CL and HPLC-CL proposed methods with SPE.

\begin{tabular}{cccccc}
\hline Method & $\begin{array}{c}\text { Initial } \\
\text { standard } \\
\text { volume }(\mathbf{m L})\end{array}$ & $\begin{array}{c}\text { Linear } \\
\text { Interval } \\
\left(\boldsymbol{\mu g} \mathbf{L}^{-1}\right)\end{array}$ & $\begin{array}{c}\text { Calibration curve } \\
\mathbf{y}=\left(\mathbf{a} \pm \mathbf{s}_{\mathbf{a}}\right)+\left(\mathbf{b} \pm \mathbf{s}_{\mathbf{b}}\right) \cdot \mathbf{C}, \\
\left(\mathbf{n}, \mathbf{r}^{2}, \mathbf{s}_{\mathbf{y} / \mathbf{x}}\right)\end{array}$ & $\begin{array}{c}\mathbf{D L} \\
\left(\boldsymbol{\mu} \mathbf{g ~ L}^{-\mathbf{1}}\right)\end{array}$ & $\begin{array}{c}\mathbf{Q L} \\
\left(\boldsymbol{\mu g} \mathbf{L}^{-1}\right)\end{array}$ \\
\hline FI-CL & 50 & $5-100$ & $\mathrm{y}=(-790 \pm 140)+(90 \pm 3) \cdot \mathrm{C}$, & 2.4 & 8.1 \\
HPLC-CL & 100 & $2.5-15$ & $\begin{array}{c}\mathrm{y}=-(12,0.99,300) \\
(1000 \pm 3000)+(9700 \pm 300) \cdot \mathrm{C}\end{array}$ & 1 & 3.3 \\
HPLC-CL & 250 & $1-6$ & $\mathrm{y}=\begin{array}{c}(-29000 \pm 5000)+(26800 \pm 1300) \cdot \mathrm{C} \\
(8,0.986,5000)\end{array}$ & 0.6 & 1.9 \\
\hline
\end{tabular}

The detection and quantification limits for this FI-CL method are also summarized in Table II. They have been calculated as $3 \cdot \mathrm{s}_{\text {blank }} / \mathrm{b}$ (detection limit, DL) or as $10 \cdot \mathrm{s}_{\text {blank }} / \mathrm{b}$ (quantification limits, QL) where $s_{\text {blank }}$ is the standard deviation of the blank signal and b is the slope of the calibration curve. A detection limit of $2.4 \mu \mathrm{g} \mathrm{L}^{-1}$ can be achieved without preconcentration. If SPE is applied to $100,250,500$ or $1000 \mathrm{~mL}$ of standard, detection limits of 1.2, 0.5, 0.2 and $0.12 \mu \mathrm{g} \mathrm{L}^{-1}$ can be reached taking into account the preconcentration factors $(2,5,10$, and 20 , respectively). The calculated detection limit with SPE $1000 \mathrm{~mL}$ was experimentally confirmed.

The precision was evaluated by repeatability (intraday precision) and reproducibility (interday precision) studies (see Table III) at three concentration levels of MCPB. The \%RSD values were below $8.2 \%$ in all cases.

The throughput of the FI-CL system was 60 hour $^{-1}$. 


\subsubsection{Figures of merit with the HPLC-CL method}

The calibration curves with SPE with $100 \mathrm{~mL}$ standards and $250 \mathrm{~mL}$ standards (final volume 1 $\mathrm{mL}$ in both cases) are shown in Table II.

The slopes of the calibration curves indicated that there are no losses of signal after the whole SPE-HPLC-CL procedure (slope with $250 \mathrm{~mL}$ is near 2.5 times higher than slope with 100 $\mathrm{mL})$.

The DLs and the QLs, calculated as $3 \cdot \mathrm{s}_{\mathrm{y} / \mathrm{x}} / \mathrm{b}$ or $10 \cdot \mathrm{s}_{\mathrm{y} / \mathrm{x}} / \mathrm{b}$, are also summarized in Table II. The preconcentration factors of 100 and 250 allowed reaching DLs of 1.0 and $0.6 \mu \mathrm{g} \mathrm{L}^{-1}$ for MCPB determination (100 and $250 \mathrm{~mL}$, respectively). Higher volumes such as $500 \mathrm{~mL}$ and $1000 \mathrm{~mL}$, allowed DLs of 0.2 and $0.1 \mu \mathrm{g} \mathrm{L}^{-1}$, respectively to be reached. The calculated DLs were experimentally confirmed.

The repeatability and reproducibility studies (Table III) provided good intraday and interday precision, the $\%$ RSD being below $9.9 \%$ in all cases.

The HPLC-CL method provided a throughput of 4 hour $^{-1}$.

Table III. Repeatability and reproducibility studies for FI-CL and HPLC-CL proposed methods with SPE.

\begin{tabular}{ccccc}
\hline Method & $\begin{array}{c}\text { Initial standard } \\
\text { volume }(\mathbf{m L})\end{array}$ & $\begin{array}{c}\text { Concentration } \\
\left(\boldsymbol{\mu} \mathbf{~ L}^{-\mathbf{1}}\right)\end{array}$ & $\begin{array}{c}\text { Intraday } \\
\text { precision } \\
\text { \% RSD (n=3) }\end{array}$ & $\begin{array}{c}\text { Interday } \\
\text { precision } \\
\text { \% RSD (n=3) }\end{array}$ \\
\hline \multirow{3}{*}{ FI-CL } & \multirow{2}{*}{50} & 10 & 7.1 & 8.2 \\
& & 25 & 4.3 & 5.6 \\
HPLC-CL & \multirow{2}{*}{100} & 0.25 & 3.4 & 4.7 \\
& & 0.5 & 8.0 & 7.4 \\
HPLC-CL & \multirow{2}{*}{250} & 1 & 2.0 & 9.9 \\
& & 0.5 & 7.3 & 1.5 \\
\hline
\end{tabular}




\subsection{Interferences}

\subsubsection{Interferences in FI-CL method}

The interference of other phenoxyacid herbicides and of the most common ions present in natural water samples was tested without SPE. Table IV shows the percentage of relative error $\left(\% \mathrm{E}_{\mathrm{r}}\right)$ and the maximum allowable concentrations (the one that varied the analytical signal by less than $10 \%$ ) for each one of the tested interfering species.

Table IV. Interferences study with FI-CL method. $\% \mathrm{E}_{\mathrm{r}}$ : percentage of relative error

\begin{tabular}{|c|c|c|}
\hline Interferent & $\begin{array}{c}\text { Maximum allowable } \\
\text { concentration } \\
\left(\mathrm{mg} \mathrm{L}^{-1}\right)\end{array}$ & $\% \mathrm{E}_{\mathrm{r}}$ \\
\hline 4-CPA & 0.05 & -9.9 \\
\hline MCPA & 0.0025 & 9.4 \\
\hline МCPP & 0.05 & 5.4 \\
\hline Diclofop & 0.075 & -6.7 \\
\hline $\mathrm{Cl}^{-}$ & 1000 & 2.8 \\
\hline $\mathrm{SO}_{4}{ }^{2-}$ & 125 & 9.1 \\
\hline $\mathrm{NO}_{3}^{-}$ & 0.04 & 5.9 \\
\hline $\mathrm{NO}_{2}^{-}$ & 40 & 8.2 \\
\hline $\mathrm{I}^{-}$ & 0.0001 & 2.2 \\
\hline $\mathrm{CO}_{3}^{2-}$ & 1 & 9.7 \\
\hline $\mathrm{Ni}^{2+}$ & 1 & 8.6 \\
\hline $\mathrm{NH}_{4}^{+}$ & 2000 & 3.6 \\
\hline $\mathrm{Co}^{2+}$ & 0.1 & 0.3 \\
\hline $\mathrm{Zn}^{2+}$ & 1 & 0.2 \\
\hline $\mathrm{Mg}^{2+}$ & 1 & 0.1 \\
\hline $\mathrm{Ca}^{2+}$ & 100 & 5.1 \\
\hline $\mathrm{Fe}^{3+}$ & 0.0001 & 7.6 \\
\hline $\mathrm{Cu}^{2+}$ & 0.1 & 8.3 \\
\hline $\mathrm{Cr}^{3+}$ & 1 & 5.6 \\
\hline $\mathrm{Cd}^{2+}$ & 100 & 2.9 \\
\hline $\mathrm{CrO}_{4}^{2-}$ & 1 & 6.6 \\
\hline $\mathrm{Mn}^{2+}$ & 0.001 & 3.8 \\
\hline $\mathrm{Pb}^{2+}$ & 0.1 & 9.3 \\
\hline
\end{tabular}

After the SPE procedure, the interference of common ions, such as $\mathrm{CO}_{3}{ }^{2-}, \mathrm{Mg}^{2+}$ and $\mathrm{Ca}^{2+}$ was eliminated. These ions pass through the cartridge without being retained, and after washing and 
drying the cartridge, they will not be present in the sorbent. Therefore, none of the studied ions would interfere at concentrations normally found in water samples.

\subsubsection{Interferences in HPLC-CL method}

In this case, after SPE procedure there were no interferences due to the cleaning and the separation processes. Moreover, only MCPB provided a significant CL emission after the HPLC separation (retention time $8.1 \mathrm{~min}$ ) which demonstrated the selectivity of the method. Figure 2c shows the chromatogram obtained without SPE for the blank and the mixture of 10 phenoxyacid herbicides with CL detection.

\subsection{Application}

The proposed HPLC-CL and FI-CL methods for the determination of MCPB were validated by spiking six different natural water samples.

\subsubsection{Application of FI-CL method}

The six water samples were fortified with MCPB at two concentration levels (generally 25 and $50 \mu \mathrm{g} \mathrm{L}^{-1}$, both concentrations assayed in triplicate). A preconcentration factor of 2 was employed for S2, S4, S5 and S6, and no preconcentration was performed for S1 and S3. SPE procedure was applied and the percentages of recovery of MCPB were calculated (see Table V). As can be seen, no matrix effect was observed for the simplest samples (S1 to S3), where the percentages of recovery were between 89 and 109\%. In the analysis of more complex samples (S4 to S6) matrix effect was observed. Thus, in these types of samples, the FI-CL method can be used as a screening method.

\subsubsection{Application of HPLC-CL method}

$100 \mathrm{~mL}$ of the six water samples were fortified with $5 \mu \mathrm{g} \mathrm{L}^{-1}$ or $10 \mu \mathrm{g} \mathrm{L}^{-1}$ of MCPB (both concentrations in triplicate, preconcentration factor of 100), SPE procedure was applied, and the percentages of recovery of MCPB were calculated (see Table V). As can be seen, the percentages of recovery were between $81 \%$ and $124 \%$. 
Table V. Percentages of recovery of MCPB in natural water samples at different levels of concentration. S1 and S2: tap water, S3: mineral water, S4: seawater, S5: spring water and S6: well water

\begin{tabular}{|c|c|c|c|c|}
\hline \multirow{3}{*}{ Sample } & \multicolumn{2}{|c|}{ FI-CL method } & \multicolumn{2}{|c|}{ HPLC-CL method } \\
\hline & \% Recovery & \% Recovery & \% Recovery & \% Recovery \\
\hline & $25 \mu g \mathrm{~L}^{-1}$ & $50 \mu \mathrm{g} \mathrm{L}^{-1}$ & $5 \mu g L^{-1}$ & $10 \mu \mathrm{g} \mathrm{L}^{-1}$ \\
\hline S1 & $109 \pm 7$ & $94.1 \pm 1.4^{\mathrm{a}}$ & $110 \pm 6$ & $110 \pm 20$ \\
\hline S2 & $89 \pm 14^{b}$ & $100 \pm 11^{\mathrm{c}}$ & $81 \pm 10$ & $98.4 \pm 1.4$ \\
\hline S3 & $98 \pm 4$ & $91.6 \pm 0.8$ & $100.5 \pm 0.3$ & $120 \pm 9$ \\
\hline S4 & $44 \pm 4$ & $59 \pm 8$ & $101 \pm 14$ & $92.4 \pm 1.5$ \\
\hline S5 & $35 \pm 5$ & $53 \pm 11$ & $120 \pm 6$ & $113 \pm 10$ \\
\hline S6 & $43 \pm 4$ & $61 \pm 3$ & $124 \pm 6$ & $99 \pm 7$ \\
\hline
\end{tabular}

${ }^{\mathrm{a}}$ Added concentration $100 \mu \mathrm{g} \mathrm{L}{ }^{-1}$

${ }^{\mathrm{b}}$ Added concentration $16 \mu \mathrm{g} \mathrm{L} \mathrm{L}^{-1}$

${ }^{c}$ Added concentration $32 \mu \mathrm{g} \mathrm{L}{ }^{-1}$

When SPE was applied to $1000 \mathrm{~mL}$ of these water samples in HPLC-CL method, MCPB was not detected. Two peaks appeared in CL chromatogram at retention times 1.4 and $6.1 \mathrm{~min}$ in samples S4, S5 and S6. These signals did not affect the determination of MCPB (retention time $8.1 \mathrm{~min})$.

The quantification of the samples that present matrix effect with FI-CL method can be solved with this HPLC-CL method.

\section{CONCLUSIONS}

Two new FI and HPLC methods with chemiluminescence detection have been proposed for the determination of the phenoxyacid herbicide MCPB. The CL emission is based on the reaction of the photodegraded MCPB and ferricyanide in basic medium.

FI-CL method combined with SPE with SDBL cartridges was found to be very sensitive. The precision of the method was good, and the interference of the common ions was eliminated by the SPE procedure. The simplest natural water samples (tap and mineral waters) can be analysed with good results, but some more complex water samples (sea, spring and well water) 
presented matrix effect. Nevertheless, this method can be employed in complex water samples with screening purposes due to its simplicity in terms of instrumentation and low cost, and its high throughput.

The proposed HPLC-CL method combined with SPE with SDBL cartridges also proved to be very sensitive. The precision of the method was good, and the interference of other herbicides of the phenoxyacid family was avoided. The accuracy of the method was validated with six natural water samples. Hence, this method is very advisable when a sensitive and selective determination of MCPB is required.

\section{REFERENCES}

[1] Pesticide Properties Database (PPDB). University of Hertfordshire. http://sitem.herts.ac.uk/aeru/ppdb/en/index.htm. [Accessed Nov 2 2014].

[2] Royal Decree 849/1986, of 11 April, by which approves the Regulation of the Hydraulic Public Domain, that Develops the Preliminary Titles, I, IV, V, VI and VII of the Law 29/1985, of 2 August, of Waters. (BOE 103, 30-Apr-1986, p. 15500). [3] Council Directive 98/83/EC of 3 November 1998 on the Quality of Water Intended for Human Consumption. Off. J. Eur. Communities: Legis. DOL 330/32, 05-12-1998.

[4] A. Moral, C. Caballo, M.D. Sicilia, S. Rubio. "Highly Efficient Microextraction of Chlorophenoxy Acid Herbicides in Natural Waters Using a Decanoic Acid-Based Nanostructured Solvent prior to their Quantitation by Liquid Chromatography-Mass Spectrometry". Anal. Chim. Acta 2012. 709: 59-65.

[5] E. Herrero-Hernández, E. Rodríguez-Gonzalo, M.S. Andrades, S. Sánchez-Gonzáles, R. Carabias Martínez. "Occurrence of Phenols and Phenoxyacid Herbicides in Environmental Waters Using an Imprinted Polymer as a Selective Sorbent”. Sci. Total Environ. 2013. 454-455: 299-306.

[6] C. Baggiani, C. Giovannoli, L. Anfossi, C. Tozzi. "Molecularly Imprinted Solid-Phase Extraction Sorbent for the Clean-Up of Chlorinated Phenoxyacids from Aqueous Samples”. J. Chromatogr. A 2001. 938: 35-44.

[7] R. Wintersteiger, B. Goger, H. Krautgartner. "Quantitation of Chlorophenoxy Acid Herbicides by High-Performance Liquid Chromatography with Coulometric Detection”. J. Chromatogr. A 1999. 846: 349-357. 
[8] M. Peruzzi, G. Bartolucci, F. Cioni. "Determination of Phenoxyalkanoic Acids and Other Herbicides at the $\mathrm{ng} / \mathrm{mL}$ Level in Water by Solid-Phase Extraction with Poly(Divinylbenzene-co-N-Vinylpyrrolidone) Sorbent and High-Performance Liquid Chromatography-Diode-Array Detection”. J. Chromatogr. A 2000. 867: 169-175.

[9] A. Ranz, E. Lankmayr. "Screening and Optimization of the Derivatization of Polar Herbicides with Trimethylanilinium Hydroxide for GC-MS Analysis”. J. Biochem. Biophys. Methods. 2006. 69: 3-14.

[10] A.A. Nuhu, C. Basheer, K. Alhooshani, A.R. Al-Arfaj. "Determination of Phenoxy Herbicides in Water Samples using Phase Transfer Microextraction with Simultaneous Derivatization followed by GC-MS Analysis”. J. Sep. Sci. 2012. 35: 3381-3388.

[11] J.J. Jiménez. "Simultaneous Liquid-Liquid Extraction and Dispersive Solid-Phase Extraction as a Sample Preparation Method to Determine Acidic Contaminants in River Water by Gas Chromatography/Mass Spectrometry”. Talanta 2013. 116: 678-687.

[12] S.A. Eremin, B. Laassis, J.J. Aaron. "Photochemical-Fluorimetric Method for the Determination of Total Chlorophenoxyacid Herbicides”. Talanta 1996. 43: 295-301.

[13] M.T. Jafari, M. Saraji, S. Yousefi. "Negative Electrospray Ionization Ion Mobility Spectrometry combined with Microextraction in Packed Syringe for Direct Analysis of Phenoxyacid Herbicides in Environmental Waters". J. Chromatogr. A 2012. 1249: 41-47.

[14] G. Z. Tsogas, D.L. Giokas, P.G. Nikolakopoulos, A.G. Vlessidis, N.P. Evmiridis. "Determination of the Pesticide Carbaryl and its Photodegradation Kinetics in Natural Waters by Flow Injection-Direct Chemiluminescence Detection”. Anal. Chim. Acta 2006. 573-574: 354-359.

[15] J.R. Albert-García, J. Martínez-Calatayud. "Determination of the Herbicide Benfuresate by its Photo-Induced Chemiluminescence using Flow Multicommutation Methodology". Talanta 2008. 75: 717-724.

[16] M. Catalá-Icardo, J.L. López-Paz, C. Choves-Barón, A. Peña-Bádena. "Native vs Photoinduced Chemiluminescence in Dimethoate Determination”. Anal. Chim. Acta 2012. 710: 81-87.

[17] C. Gómez-Benito, S. Meseguer-Lloret, S. Torres-Cartas. "Sensitive Determination of Fenamiphos in Water Samples by Flow Injection Photoinduced Chemiluminescence”. Int. J. Env. Anal. Chem. 2013. 93(2): 152-165. 
[18] D.J. Beale, N.A. Porter, F. A. Roddick. "A Fast Screening Method for the Presence of Atrazine and Other Triazines in Water using Flow Injection with Chemiluminescent Detection". Talanta 2009. 78: 342-347.

[19] M. Catalá-Icardo, J.L. López-Paz, L.M. Pérez-Plancha. "Fast Determination of Thiacloprid by Photoinduced Chemiluminescence”. Appl. Spectrosc. 2014. 68(6): 642-648.

[20] S. Torres-Cartas, C. Gómez-Benito, S. Meseguer-Lloret. "FI On-Line Chemiluminescence Reaction for Determination of MCPA in Water Samples”. Anal. Bioanal. Chem. 2012. 402(3): 1289-1296.

[21] M. Catalá-Icardo, L. Lahuerta-Zamora, S. Torres-Cartas, S. Meseguer-Lloret. "Determination of Organothiophosphorus Pesticides in Water by Liquid Chromatography and Post-Column Chemiluminescence with Cerium (IV)". J. Chromatogr. A 2014. 1341: $31-40$.

[22] J.F. Huertas-Pérez, A.M. García-Campaña. "Determination of N-methylcarbamate Pesticides in Water and Vegetable Samples by HPLC with Post-Column Chemiluminescence Detection using the Luminol Reaction”. Anal. Chim. Acta 2008. 630: 194-204.

[23] E. Orejuela, M. Silva. "Monitoring some Phenoxyl-type N-methylcarbamate Pesticide Residues in Fruit Juices using High-Performance Liquid Chromatography with Peroxyoxalate-Chemiluminescence Detection”. J. Chromatogr. A 2003. 1007: 197-201.

[24] M. Martínez Galera, M.D. Gil García, R. Santiago Valverde. "Determination of Photoirradiated High Polar Benzoylureas in Tomato by HPLC with Luminol Chemiluminescence Detection”. Talanta 2008. 76: 815-823.

[25] N. Rosales-Conrado, M.E. León-González, L.V. Pérez-Arribas, L.M. Polo-Díez. "Effect of Temperature on the Separation of Chlorophenoxy Acids and Carbamates by Capillary High-Performance Liquid Chromatography and UV (or Diode Array) Detection". J. Chromatogr. A 2005. 1081: 114-121.

[26] R.B. Geerdink, S. Van Tol-Wildenburg, W.M.A. Niesse, U.A.Th. Brinkman. "Determination of Phenoxy Acid Herbicides from Aqueous Samples by Improved Cleanup on Polymeric Precolumns at High pH”. Analyst 1997. 122: 889-893. 